Research Article

\title{
Research on the Seismic Performance of the Prefabricated Reinforced Concrete Column with Steel Mortise and Tenon Connections
}

\author{
Jun Yan $(\mathbb{D})$ and Lianjie Jiang (iD) \\ School of Civil Engineering and Architecture, Suqian University, Suqian 223800, Jiangsu, China \\ Correspondence should be addressed to Jun Yan; kindrascal@126.com
}

Received 7 October 2020; Revised 29 November 2020; Accepted 5 January 2021; Published 16 January 2021

Academic Editor: Hayri Baytan Ozmen

Copyright (c) 2021 Jun Yan and Lianjie Jiang. This is an open access article distributed under the Creative Commons Attribution License, which permits unrestricted use, distribution, and reproduction in any medium, provided the original work is properly cited.

\begin{abstract}
In this study, 6 prefabricated reinforced concrete columns with different lengths of connectors and thicknesses of the steel plate used in connectors and 1 cast-in-place reinforced concrete column were made, and then these specimens were tested under the low cycled reversed loading experiment to study the seismic performance of the prefabricated reinforced concrete columns with steel mortise and tenon connections. The failure mode, bearing capacity, ductility, stiffness degradation, and energy dissipation of the specimens were analyzed. The results show that compared with the cast-in-place specimens, the bearing capacity of the fabricated specimen is reduced by $5.77 \%-16.67 \%$, but the ductility is increased by $11.28 \%-26.69 \%$, and the cumulative energy consumption is increased by $3.40 \%-30.29 \%$; the stiffness, bearing capacity degradation, and hysteretic behavior of the fabricated specimen under different displacement angles are less different from those of the cast-in-place specimens. When the length of the connector is $100 \mathrm{~mm}$ and the thickness of the steel plate used in the connector is $4 \mathrm{~mm}$, the weld fracture may occur in the connection area of the fabricated specimen. The test results show that when the connector with a length of $100 \mathrm{~mm}$ is used, the thickness of the steel plate of the connector should not be less than $6 \mathrm{~mm}$.
\end{abstract}

\section{Introduction}

As the main trend of modern architecture, the industrialization of architecture has the following characteristics: the standardization of component design, factorization of component production, and assembly of the construction process [1]. Experimental and theoretical studies on fabricated structures have been widely performed by scholars [2-6]. The research results show that the working performance of the structure is directly determined by the connection quality of the prefabricated concrete column. Generally, there are two kinds of connection modes: wet connection and dry connection. Scholars have carried out a lot of research studies on the mechanical performance of the prefabricated concrete column.

In the previous study, Li et al. [7] carried out the seismic performance test on the fabricated concrete column with partially encased steel tubular. The results showed that the bearing capacity, seismic performance, and integrity of the prefabricated concrete column are better than those of the cast-in-place concrete column. Besides, the calculation equation of the bearing capacity of the normal section of the prefabricated column joint was proposed. Wang et al. [8] regarded the form of tooth groove and tooth height as variable parameters and conducted the low cycled reversed loading experiment of the prefabricated frame columns. The results showed that the fully assembled reinforced concrete columns with welded connections are reliable and have the same bearing capacity and seismic performance as the castin-place concrete. Liu et al. [9] used the assembly structure and axial compression ratio as variable parameters, performed the seismic performance test of full-scale prefabricated reinforced concrete columns, and analyzed the bearing capacity, stiffness, deformation performance, and hysteretic energy dissipation of the specimens. The results showed that the performance of the prefabricated concrete 
column with improved longitudinal reinforcement is the same as that of cast-in-place reinforced concrete, but the overlapped zone of longitudinal reinforcement may break under the larger displacement angle. Liu et al. [10] conducted the experimental study on the axial compression performance of the prefabricated reinforced concrete columns with the concave-convex assembled connection structure during the construction. The bearing mechanism of assembled reinforced concrete columns under the axial compression was analyzed, and the calculation equation of axial bearing capacity was proposed. Yan et al. [11, 12] carried out the seismic performance test of the prefabricated reinforced concrete columns with the single straight slot, single slope slot, double straight slot, and double slope slot. The results show that, with the reliable working performance, the fabricated concrete column with steel slotted connection has the same seismic performance index as the cast-in-place concrete column, which can meet the requirements of engineering practice.

In this paper, the prefabricated concrete column with steel mortise and tenon connections was proposed. The longitudinal reinforcement at the head of upper and lower precast columns was pasted and welded on the inner wall of steel mortise and tenon connectors. The prefabricated upper and lower columns were assembled by steel mortise and tenon connectors and then connected by welding as a whole. Figure 1 shows this structure with clear force transmission. In this paper, the thickness of steel plates used in the connector, the length of the connector, and connection position were taken as variable parameters. Subsequently, 6 prefabricated reinforced concrete columns and 1 cast-inplace reinforced concrete column were tested by quasi-static tests. The failure mode, hysteretic curve, skeleton curve, bearing capacity, ductility, stiffness degradation, strength degradation, and energy consumption of the specimens were analyzed. This study provides a reference to the application of the fabricated concrete with steel mortise and tenon connections.

\section{Experimental Processes}

2.1. Specimen Design. Six prefabricated reinforced concrete column specimens with steel mortise and tenon connections at geometric dimensions of $1 / 2$ (specimen nos. PRC1-1, PRC2-1, PRC3-1; PRC1-2, PRC2-2, PRC3-2) were designed and manufactured, and one cast-in-place reinforced concrete column (specimen no. RC) was prepared as the contrast specimen. These specimens had the same geometric dimensions. The section size of the specimen was $250 \mathrm{~mm} \times 250 \mathrm{~mm}$, the column height was $1600 \mathrm{~mm}$, the longitudinal reinforcement in the column was $8 \mathrm{C} 20$, the reinforcement ratio at one side was $1.79 \%$, and the stirrup was 1.79\% C8@80. The size of the RC ground beam was $400 \mathrm{~mm} \times 500 \mathrm{~mm}$, and the length was $1300 \mathrm{~mm}$.

The steel mortise and tenon connector were welded with the Q235 steel plate in connection mode A and connection mode $B$. The total size of the steel mortise and tenon connector in connection mode A after assembly was $(194+2 t) \mathrm{mm} \times(194+2 t) \mathrm{mm} \times 200 \mathrm{~mm}$, in which the tenon size was $100 \mathrm{~mm} \times 100 \mathrm{~mm} \times(100-2 t) \mathrm{mm}$, and the mortise size was $100 \mathrm{~mm} \times 100 \mathrm{~mm} \times(100-t) \mathrm{mm}$; the overall size of the steel mortise and tenon connector in connection mode $\mathrm{B}$ after assembly was $(194+2 t) \mathrm{mm} \times(194+2 t) \mathrm{mm} \times 400 \mathrm{~mm}$, in which the tenon size was $100 \mathrm{~mm} \times 100 \mathrm{~mm} \times 100 \mathrm{~mm}$, and the mortise size was $100 \mathrm{~mm} \times 100 \mathrm{~mm} \times 100 \mathrm{~mm}$. And $t$ is the thickness of the steel plate of the connector. Figure 2 shows the steel mortise and tenon connector in detail.

The longitudinal reinforcement inside the column and the inner surface of the connector were welded on both sides, as shown in Figure 3. The electrode arc welding was used with the basic electrode E5015. For connection mode A, the weld length was $100 \mathrm{~mm}$; for connection mode $\mathrm{B}$, the weld length was $200 \mathrm{~mm}$, and the welding foot size $h_{f}^{\prime}$ was $6 \mathrm{~mm}$.

Connection method A was used for specimens PRC1-1, PRC2-1, and PRC3-1, and the thickness of the steel plate used in the connector was $4 \mathrm{~mm}, 6 \mathrm{~mm}$, and $8 \mathrm{~mm}$, respectively. Connection mode $\mathrm{B}$ was used for specimens PRC1-2, PRC2-2, and PRC3-2, and the thickness of the steel plate was $4 \mathrm{~mm}, 6 \mathrm{~mm}$, and $8 \mathrm{~mm}$, respectively; the longitudinal reinforcement in the column was welded with the inner wall of the steel mortise and tenon connector, and no stirrup was set in the connection area. The total steel consumption of the cast-in-place specimens was $111.42 \mathrm{~kg}$ and that of the prefabricated specimens PRC1-PRC3-2 was $118.592 \mathrm{~kg}, 123.667 \mathrm{~kg}, 128.742 \mathrm{~kg}, 122.375 \mathrm{~kg}, 129.936 \mathrm{~kg}$, and $137.497 \mathrm{~kg}$, respectively. Compared with the cast-inplace specimens, the total steel consumption of the prefabricated specimens PRC1-PRC3-2 increased by $6.4 \%$, $10.99 \%, 15.55 \%, 9.83 \%, 16.62 \%$, and $23.40 \%$, respectively. The axial compression ratio of all specimens was 0.2 , the length from the loading point to the column root was $1350 \mathrm{~mm}$, and the shear span ratio was 5.4. Table 1 shows the design parameters of specimens, and Figure 4 shows the specific size and reinforcement.

The concrete design strength of the specimen was C40, and commercial concrete was used. Three $150 \mathrm{~mm} \times 150 \mathrm{~mm} \times 150 \mathrm{~mm}$ cube concrete test blocks and three $150 \mathrm{~mm} \times 150 \mathrm{~mm} \times 300 \mathrm{~mm}$ prism concrete test blocks were made during the pouring of the specimens. The average compressive strength of the concrete cube was 48.53 $\mathrm{MPa}$, and the average axial compressive strength was 45.03 $\mathrm{MPa}$. The properties of steel materials were tested by the uniaxial tensile test, and the determined strength indexes are shown in Table 2.

2.2. Loading Device and Loading System. The "cantilever" quasi-static loading method [13] was adopted. Figure 5 shows the test device in this study. The vertical load was determined by the test axial pressure ratio, applied to the column top by a $2000 \mathrm{kN}$ ultrahigh stabilized pressure oil pump jack, and kept constant during the test. A one-way rotating hinge was placed between the column top and the jack to ensure that the column top can rotate freely in the loading direction. A sliding car with the low friction was placed between the jack and the reaction frame beam to ensure that the vertical jack can move with the horizontal displacement of the column top. The base of the specimen 


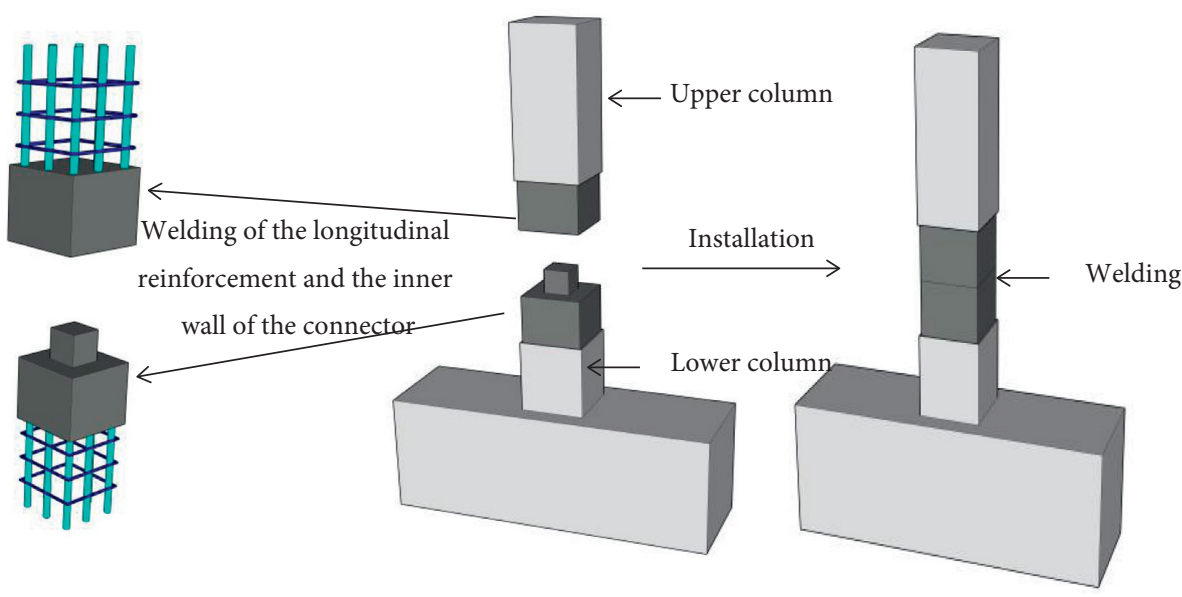

FIgURE 1: Design idea of the prefabricated reinforced concrete column with steel mortise and tenon connections.

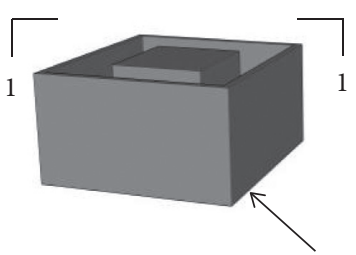

Mortise

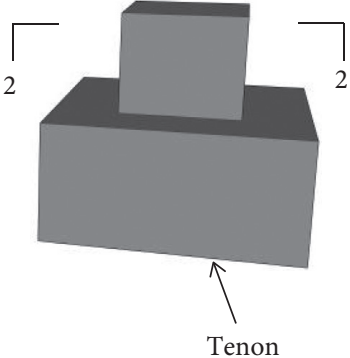

Tenon

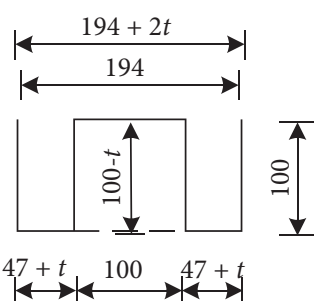

$1-1$

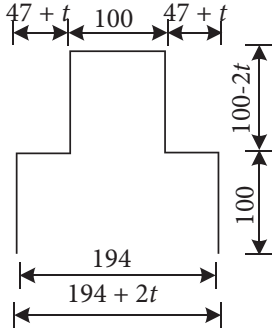

$\underline{2-2}$

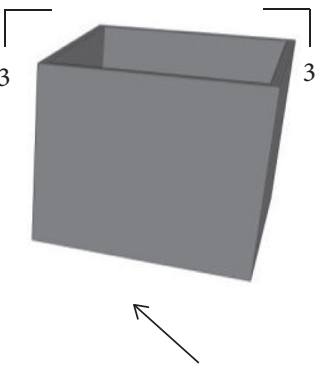

Mortise

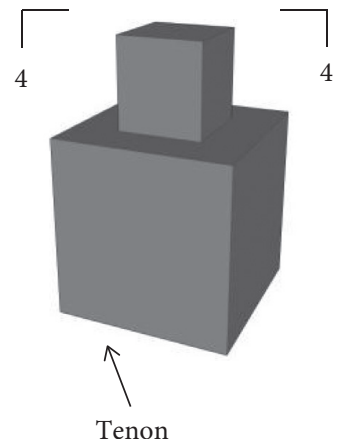

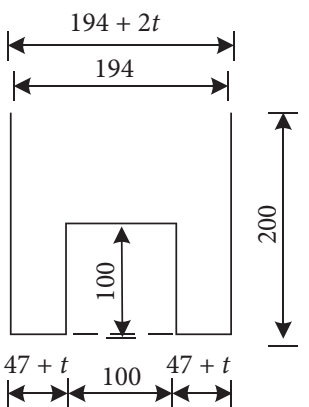

$\underline{3-3}$

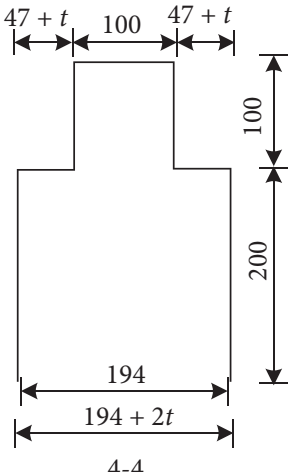

$\underline{4-4}$

(a)

(b)

Figure 2: Details of the steel mortise and tenon connector (mm). (a) Connection mode A. (b) Connection mode B.

was fixed on the rigid ground by the steel beam and anchor screw to prevent the horizontal slipping of specimens during the loading process. The horizontal load was applied by the MTS electrohydraulic servo loading system (range: $1000 \mathrm{kN}$ ), and the height from the loading center to the bottom of the column was $H=1350 \mathrm{~mm}$.

After the specimen was installed, $20 \%$ of the predetermined vertical load was applied to the top of the column. Whether the specimen aligned with the vertical force was determined by the strain change of the longitudinal reinforcement at the root of the column, and the normal operation of all instruments was verified. When the calibration work was completed, the unloading was conducted. At the beginning of the test, the vertical load was applied to the predetermined value and remained constant during the test.

The whole loading process was controlled by the displacement. Before the specimen reached the yield load, the horizontal displacement angles were 1/1000, 1/800, 1/500, 1/ $300,1 / 250,1 / 200,1 / 150,1 / 100$, etc., and each displacement 


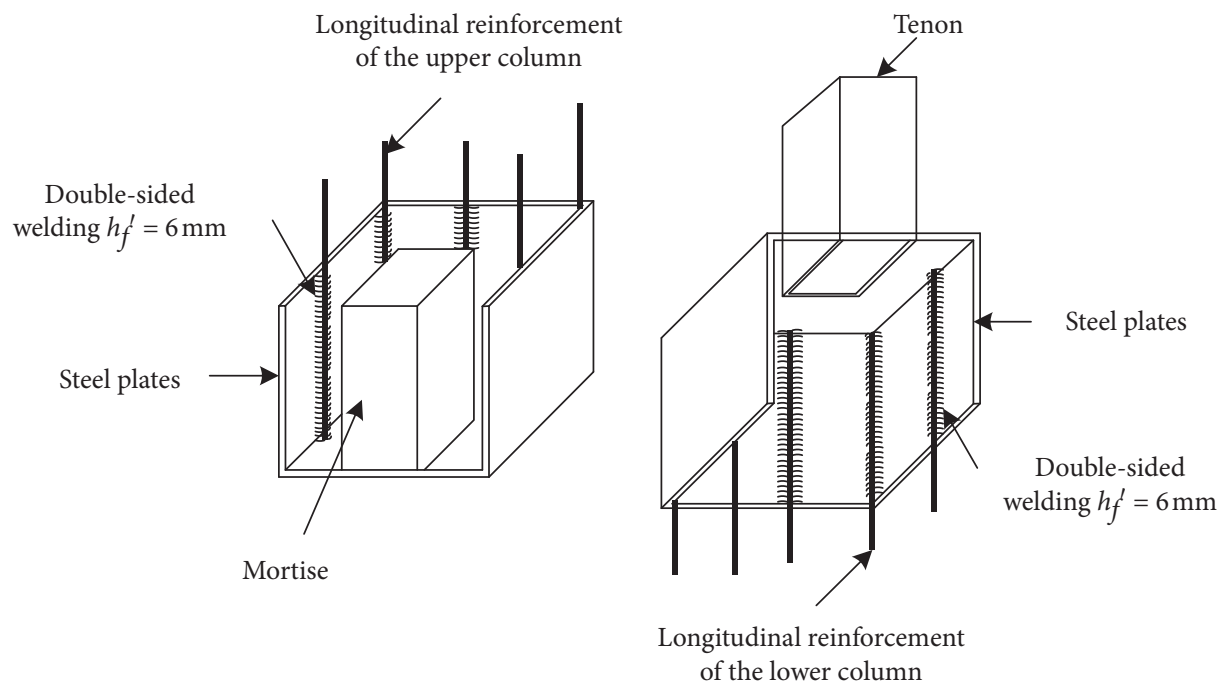

(a)

(b)

Figure 3: The welding of the steel bars on the inner face of the connector: (a) mortise; (b) tenon.

TABLE 1: Design parameters of specimens.

\begin{tabular}{lcccccc}
\hline $\begin{array}{l}\text { Specimen } \\
\text { no. }\end{array}$ & $\begin{array}{c}\text { Section size } \\
(\mathrm{mm} \times \mathrm{mm})\end{array}$ & $\begin{array}{c}\text { Thickness of the steel plate } \\
t(\mathrm{~mm})\end{array}$ & $\begin{array}{c}\text { Connection } \\
\text { mode }\end{array}$ & $\begin{array}{c}\text { Shear span } \\
\text { ratio }\end{array}$ & $\begin{array}{c}\text { Axial compression } \\
\text { ratio }\end{array}$ & $\begin{array}{c}\text { Concrete strength } \\
\text { grade }\end{array}$ \\
\hline RC & $250 \times 250$ & - & - & 5.4 & 0.2 & C50 \\
PRC1-1 & $250 \times 250$ & 4 & $\mathrm{~A}$ & 5.4 & 0.2 & C50 \\
PRC2-1 & $250 \times 250$ & 6 & $\mathrm{~A}$ & 5.4 & 0.2 & \\
PRC3-1 & $250 \times 250$ & 8 & $\mathrm{~A}$ & 5.4 & 0.2 & C50 \\
PRC1-2 & $250 \times 250$ & 4 & $\mathrm{~B}$ & 5.4 & 0.2 & C50 \\
PRC2-2 & $250 \times 250$ & 6 & $\mathrm{~B}$ & 5.4 & 0.2 & C50 \\
PRC3-2 & $250 \times 250$ & 8 & $\mathrm{~B}$ & 5.4 & 0.2 & C50 \\
\hline
\end{tabular}

was cycled once. When the specimen reached the yield displacement $\Delta_{y}$, the loading placement was $1.0 \Delta_{y}, 1.5 \Delta$, $2.0 \Delta_{y}, 2.5 \Delta_{y}, 3.0 \Delta_{y}$, and $1.5 \Delta_{y}$, and each displacement was cycled three times. When the horizontal load dropped below $85 \%$ of the maximum load or the hysteretic curve was unstable, the test was terminated.

2.3. Measurement Parameters. The main measurement parameters in the test process included (1) the horizontal load and horizontal displacement at the top of each specimen, which were collected automatically by the MTS system; (2) the strain of longitudinal reinforcement, stirrup at the root of the column, and steel mortise-tenon connector, which was measured by the resistance strain gauge pasted on the surface of longitudinal reinforcement, stirrup, and connector and then collected by the DH3816 static strain test system; (3) crack generation, development, and distribution of the specimen; and (4) the horizontal slip of the specimen base, which was measured by the displacement meter at the base end in the loading direction and collected by the DH3816 static strain test system.

\section{Experimental Results and Analysis}

3.1. Experimental Results. The failure process of all specimens can be divided into four stages: cracking stage, yield stage, peak stage, and ultimate stage. Bending failure is the final failure mode of specimens, as shown in Figure 6 (the small picture shows the side failure mode of each specimen).

3.1.1. Cracking Stage. At this stage, the displacement is small, the horizontal load increases with the increase of loading displacement, and the specimen has no obvious change. For specimen RC, when the loading displacement angle is $1 / 287$, the first horizontal bending crack appears at $20 \mathrm{~mm}$ from the bottom of the column on the left side of the specimen, the crack length is $15 \mathrm{~mm}$, and the cracking load is $42.31 \mathrm{kN}$. For PRC1-1, when the loading displacement angle is $1 / 600$, the first crack appears on the left side and $240 \mathrm{~mm}$ from the bottom, and the cracking load is $25.96 \mathrm{kN}$. For PRC1-2, PRC2-1, PRC2-2, PRC3-1, and PRC3-2, when the loading displacement angle is $1 / 300$, the first crack appears in the range of $30 \mathrm{~mm}-160 \mathrm{~mm}$ from the bottom of the column and on one side of the specimen, and the cracking 


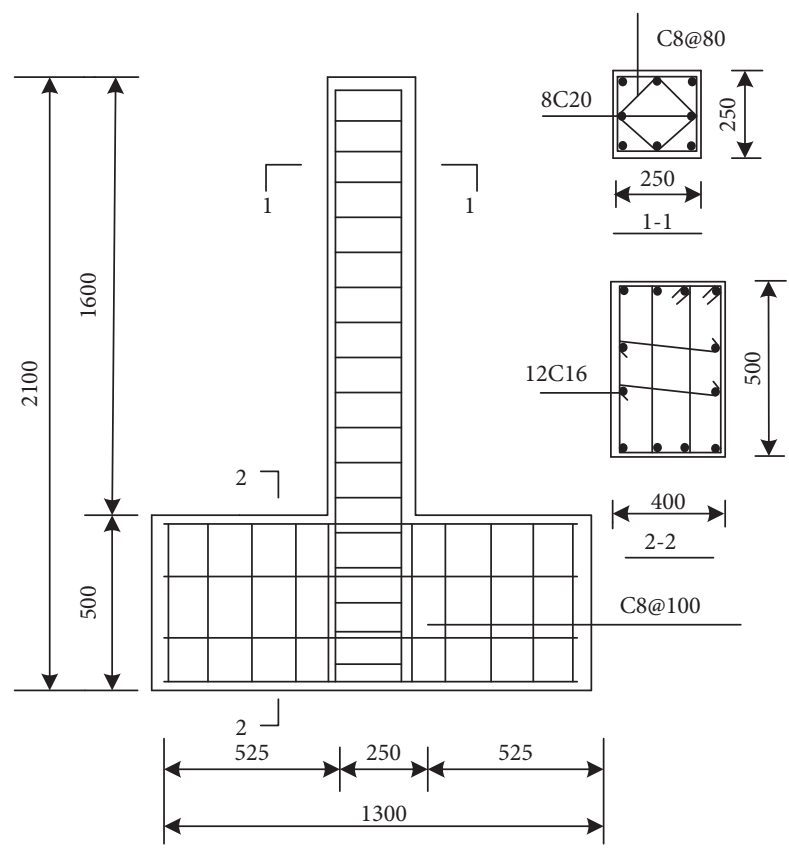

(a)

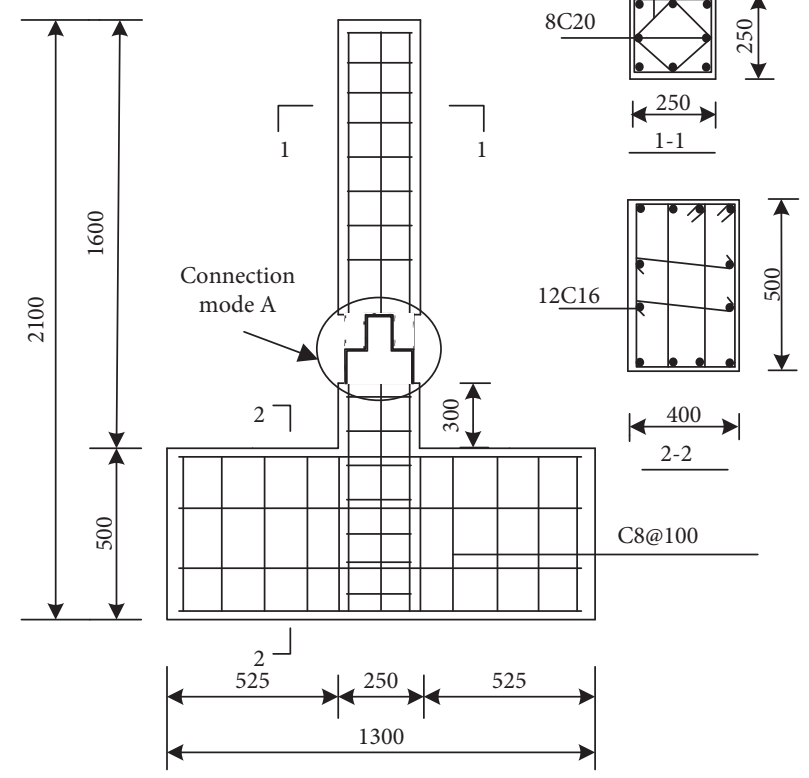

(b)

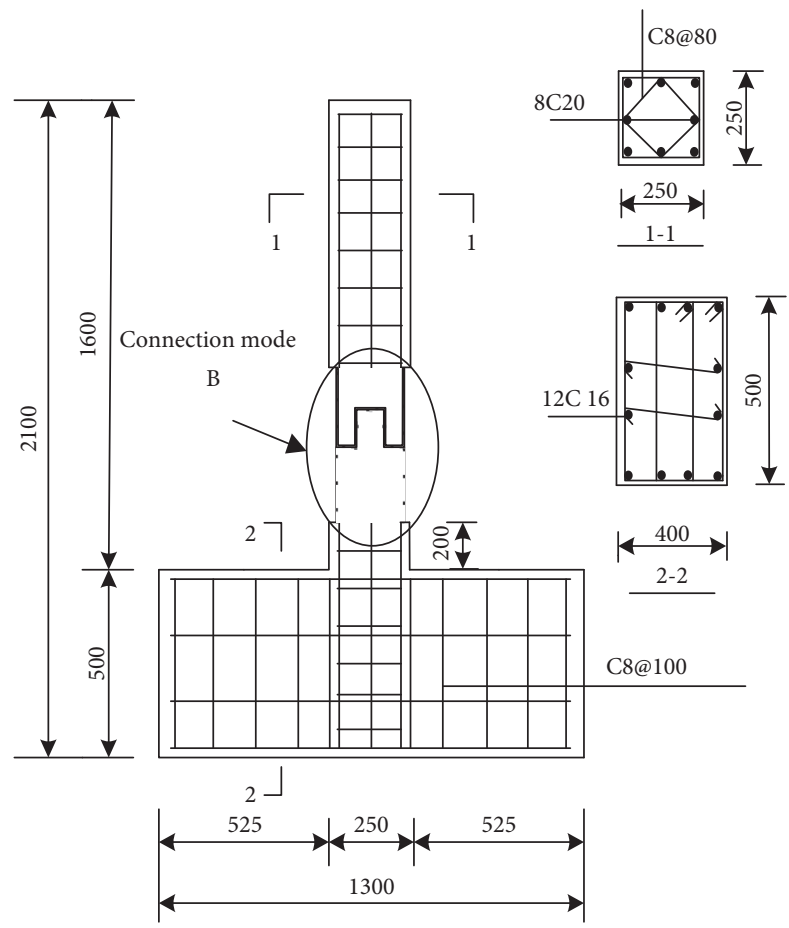

(c)

FIGURE 4: Specimen size and section reinforcement: (a) cast-in-place specimen RC, (b) specimens PRC1-1, PRC2-1, and PRC3-1, and (c) specimens PRC1-2, PRC2-2, and PRC3-2.

TABLE 2: Steel material properties.

\begin{tabular}{lccc}
\hline Reinforcement type & Yield strength $f_{y}(\mathrm{MPa})$ & Ultimate strength $f_{b}(\mathrm{MPa})$ & Elastic modulus $E_{s}(\mathrm{GPa})$ \\
\hline C20 & 498 & 660 & 207 \\
C8 & 430 & 550 & 204 \\
Steel plate (Q235) & 335 & 450 & 210 \\
\hline
\end{tabular}




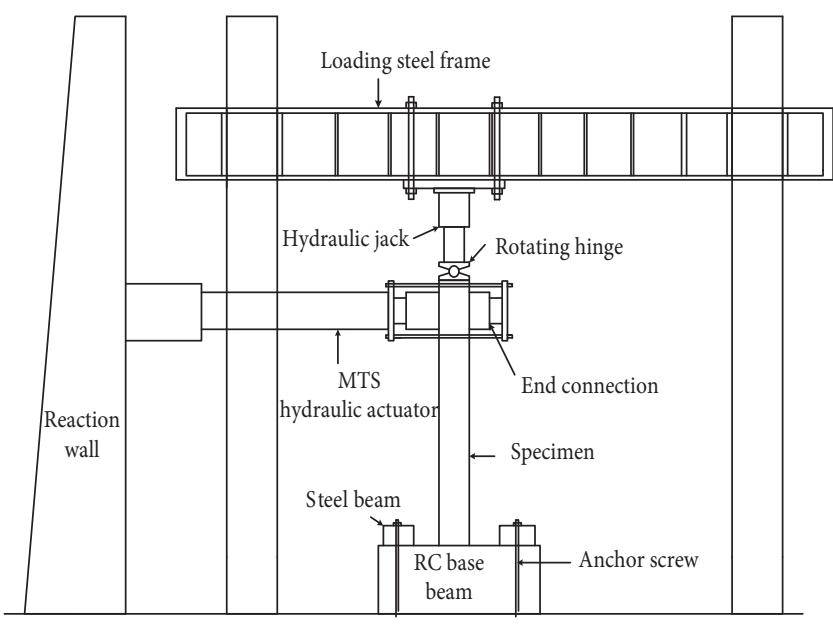

(a)

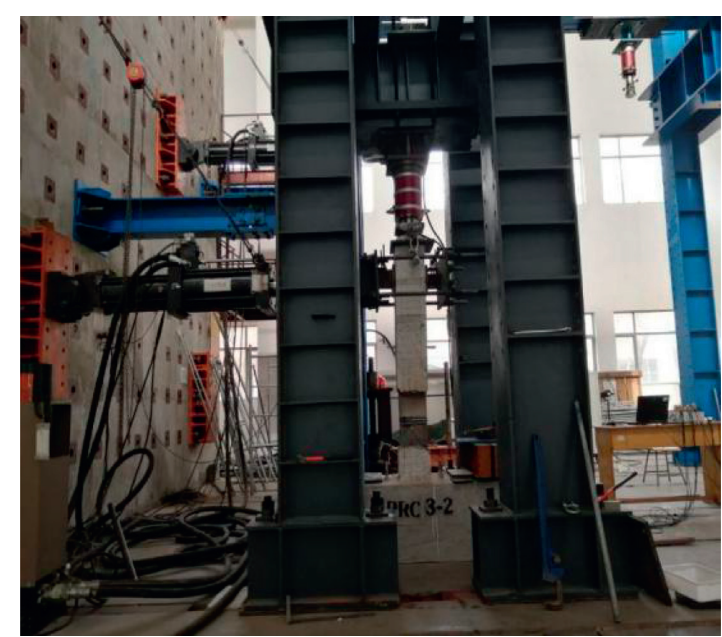

(b)

Figure 5: Test loading device: (a) schematic diagram of the test loading device; (b) loading device in field test.

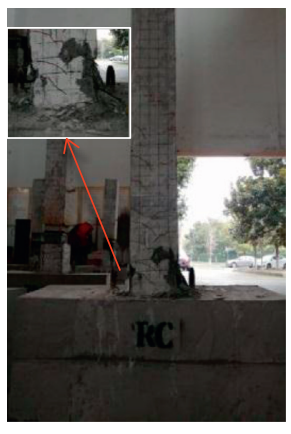

(a)

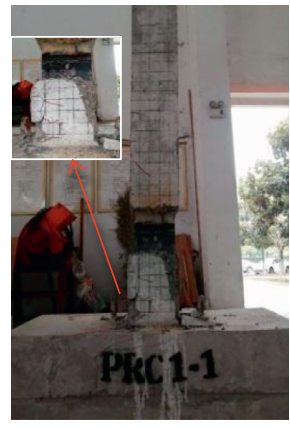

(b)

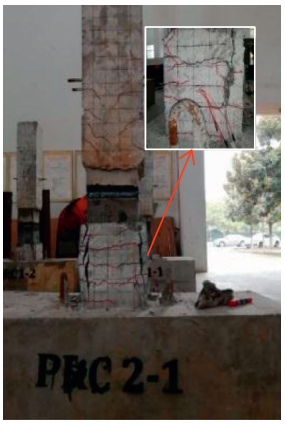

(c)

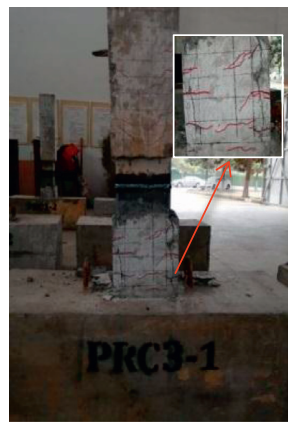

(d)

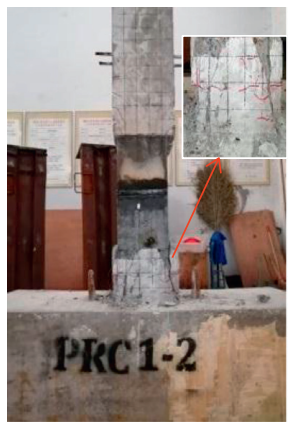

(e)

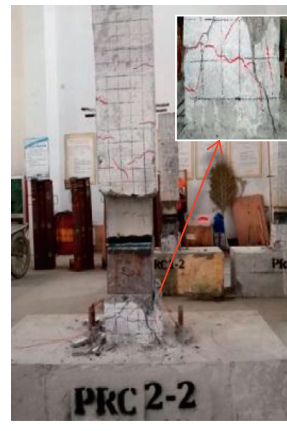

(f)

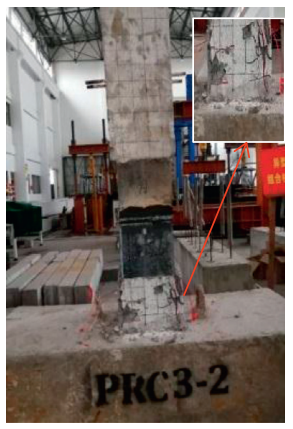

(g)

FIGURE 6: Failure mode of specimens: (a) specimen RC, (b) specimen PRC1-1, (c) specimen PRC2-1, (d) specimen PRC3-1, (e) specimen PRC1-2, (f) specimen PRC2-2, and (g) specimen PRC3-2.

loads are $25.84 \mathrm{kN}, 26.36 \mathrm{kN}, \quad 38.45 \mathrm{kN}, \quad 35.1 \mathrm{kN}$, and $29.94 \mathrm{kN}$, respectively. It can be seen that the cracking displacement angle and the cracking load of the fabricated specimens are slightly smaller than those of the cast-in-place specimens, and there is no significant difference between the fabricated specimens.

3.1.2. Yield Stage. This stage is from the cracking of the specimen to the yield of the specimen. The yield of the specimen is marked by the tensile yield of the longitudinal reinforcement. In the early stage, with the increase of the loading displacement angle, the number of horizontal bending cracks increases; when unloading is performed, the cracks are closed. In the later stage, new cracks are no longer generated, the crack width continues to increase within $0.1 \mathrm{~mm}$, and crack closure does not occur. For specimen RC, when the loading displacement angle is $1 / 125$, the maximum tensile strain of longitudinal reinforcement is $2.457 \times 10^{-3}$, the maximum compressive strain is $1.723 \times 10^{-3}$, and the specimens yield. The yield displacement angles of PRC11-PRC3-2 specimens are 1/125, 1/100, 1/100, 1/100, 1/125, 
and $1 / 150$, respectively; the yield loads (taking the average value of absolute values of forward and reverse loads) are $70.81 \mathrm{kN}, \quad 76.23 \mathrm{kN}, 76.27 \mathrm{kN}, 72.68 \mathrm{kN}, \quad 65.25 \mathrm{kN}$, and $71.91 \mathrm{kN}$, respectively. Through comparison, it can be found that the cracks of specimen RC are distributed within $600 \mathrm{~mm}$ at the bottom of the specimens, while the cracks of fabricated specimens are mainly distributed in the range from the lower end of the connector to the column bottom, that is, $300 \mathrm{~mm}-400 \mathrm{~mm}$ away from the bottom of the specimens. The main reason is that the steel mortise and tenon connector blocks the upward development of the cracks; the yield load of the specimens in connection mode B is slightly higher than that of the specimens in connection mode $\mathrm{A}$.

3.1.3. Peak Stage. At this stage, the specimens yield until reaching the peak load. With the increase of the loading displacement angle, there are no new cracks in each specimen. The original horizontal cracks on the left and right sides continue to extend; finally, through cracks are formed. The original cracks in the front and back begin to develop towards $45^{\circ}$, forming the cross-cracks gradually. The crack width is distributed in the range of $0.6 \mathrm{~mm}-1.0 \mathrm{~mm}$. When the load is close to the peak value, all specimens peel off. For RC, when the loading displacement angle is $1 / 40$, the specimen reaches the peak load (taking the average value of the absolute value of forward and reverse peak loads) $P_{b}=106.16 \mathrm{kN}$, and the concrete at the bottom of the right side of the specimen is crushed, and the crushing height is $150 \mathrm{~mm}$. For PRC1-1-PRC3-2, when the loading displacement angle (taking the average value of displacement angles of forward and reverse peaks) is 1/43.5, 1/42.3, 1/53.8, 1/50.3, $1 / 54.6$, and $1 / 54.1$, the specimens reach the peak loads of $100.03 \mathrm{kN}, 95.50 \mathrm{kN}, 96.34 \mathrm{kN}, 91.94 \mathrm{kN}, 88.37 \mathrm{kN}$, and $97.94 \mathrm{kN}$, respectively. It should be pointed out that when the displacement angle of the PRC1-1 specimen is $1 / 40$, the weld joint of the left side of the specimen is broken, the fracture length is $55 \mathrm{~mm}$, and the steel plate of the tenon component bulges outward, and the other fabricated specimens have no obvious change. The analysis results show that the peak displacement angle and peak load of the fabricated specimen are smaller than those of the cast-inplace specimen, and the peak displacement angle of the fabricated specimen in connection $A$ is smaller than that of the fabricated specimen in connection B.

3.1.4. Ultimate Stage. This stage starts from the peak load to the failure of the specimen. At this stage, with the increase of the loading displacement, the horizontal load decreases continuously, and the spalling of the concrete in the protective layer of each specimen is aggravated. Finally, the concrete at the root of the two sides of the specimen is crushed to form a plastic hinge, and the specimen failure occurs. The height of the plastic hinge of RC is $170 \mathrm{~mm}$, that of fabricated specimens with connection mode A is $300 \mathrm{~mm}$, and that of fabricated specimens with connection mode $\mathrm{B}$ is $200 \mathrm{~mm}$. The ultimate displacement angle of RC is $1 / 33.5$, and the ultimate load is $91.93 \mathrm{kN}$; the ultimate displacement angle of specimens PRC1-1-PRC3-2 is 1/33.1, 1/31.5, 1/32.7, $1 / 31.2,1 / 33.2$, and $1 / 31.4$, and the corresponding ultimate load (taking the average value of forward and reverse ultimate loads) is $92.97 \mathrm{kN}, 84.29 \mathrm{kN}, 81.9 \mathrm{kN}, 77.98 \mathrm{kN}$, $73.08 \mathrm{kN}$, and $83.21 \mathrm{kN}$, respectively.

To sum up, the fabricated specimens with connection modes A and B all have good overall working performance, but the connection weld fracture of the PRC1-1 specimen occurs during the test. This is mainly caused by the thinner steel plate of the connector and the shallow weld depth. Therefore, if connection mode A is adopted, it is recommended that the thickness of the steel plate should not be less than $6 \mathrm{~mm}$. The rest of the connectors are not damaged, which can meet the force transmission requirements of the connecting parts.

3.2. Longitudinal Reinforcement Strain. Figure 7 shows the hysteretic curve of the horizontal load-longitudinal reinforcement strain at the root of the specimen. It can be concluded that, (1) in general, the strain development law of longitudinal reinforcement in each specimen is similar. The tensile and compressive strains of longitudinal reinforcement increase with the increase of horizontal loads. Before yield load, the strain increase rate of longitudinal reinforcement is small, and after yield load, the increased rate of longitudinal reinforcement strain significantly increases. All specimens show large eccentric compression failure mode, and the strength of longitudinal reinforcement is fully used; (2) according to Figure 7(b), the longitudinal reinforcement of PRC1-1 does not yield under the compression due to the weld fracture in the connection area. With the increase of loading displacement, the rotation point moves up to the joint of upper and lower columns; (3) the yield displacement angle and yield load of the fabricated specimen are smaller than those of the cast-in-place specimen; and (4) in the same connection mode, the thicker the connecting steel plate, the smaller the yield load and yield displacement of the fabricated specimen. At the same thickness of the steel plate, the yield load and yield displacement of the fabricated specimen using connection mode B are lower than those of the fabricated specimen using connection mode $\mathrm{A}$.

3.3. Hysteresis Curve. Figure 8 shows the hysteretic curve of the horizontal load-displacement angle of each specimen. In this figure, $P$ is the horizontal load of the loading point, and $\Delta$ is the horizontal displacement of the loading point.

(1) The hysteretic curves of the specimens are full and fusiform without an obvious pinch. It indicates that the specimens have good energy consumption capacity.

(2) Before the peak load, the difference of the hysteretic curve between the fabricated specimen and the castin-place specimen is small. After the peak load, the slope of the descending section of the hysteretic curve of cast-in-place RC is significantly greater than that of the fabricated specimen. It indicates that the 


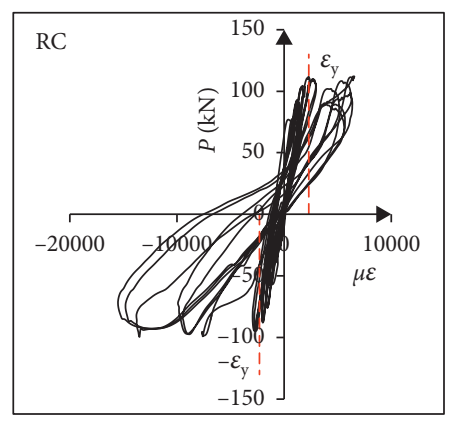

(a)

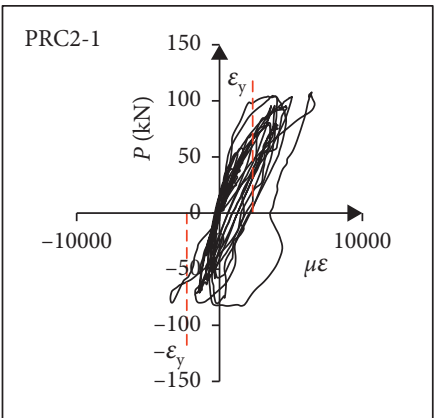

(d)

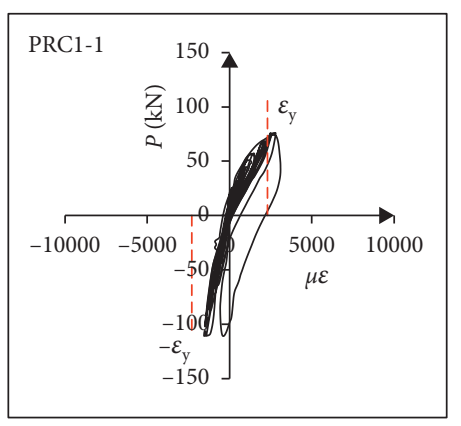

(b)

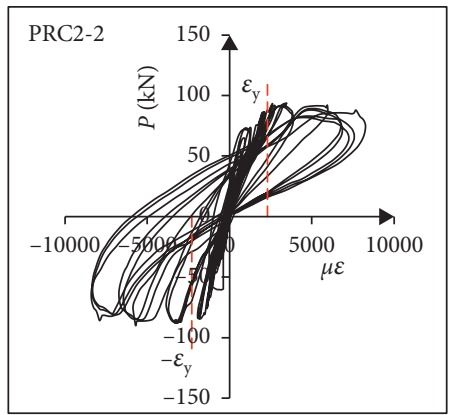

(e)

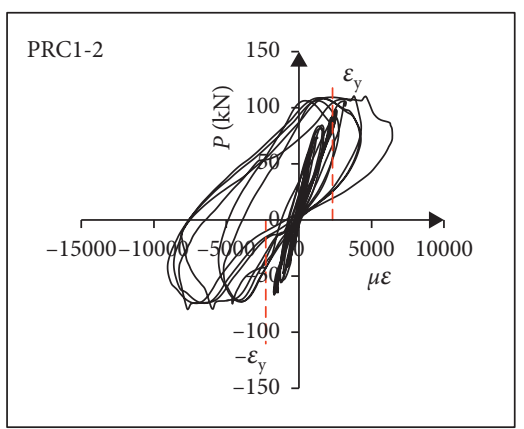

(c)

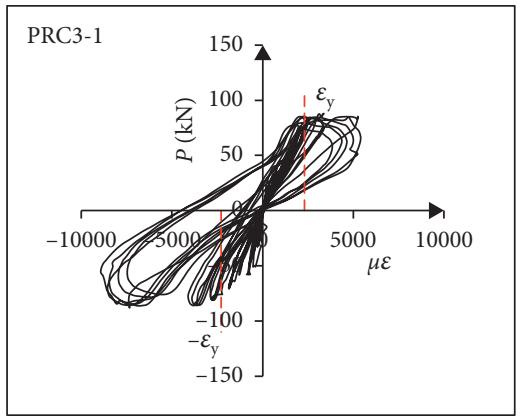

(f)

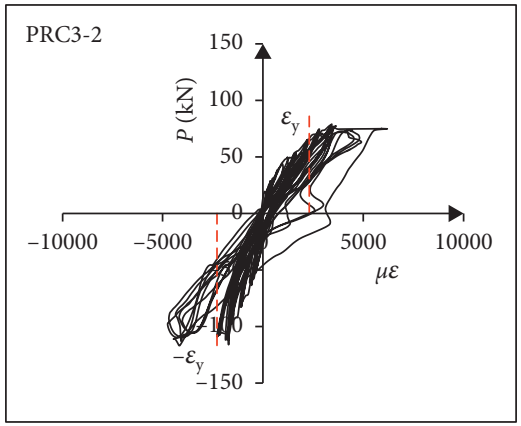

(g)

Figure 7: Hysteretic curves of longitudinal reinforcement strain versus horizontal load.

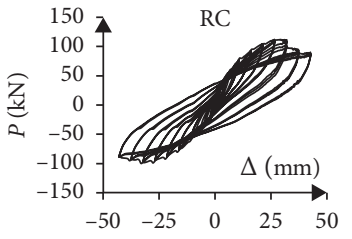

(a)

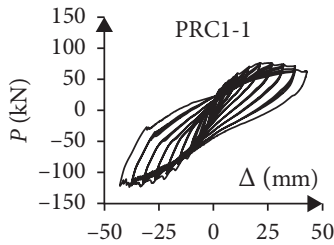

(b)

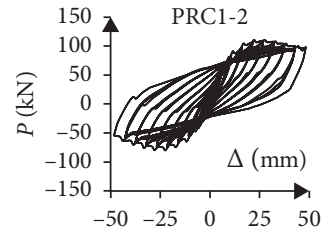

(c)

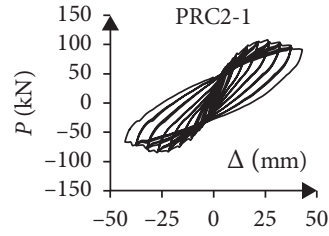

(d)

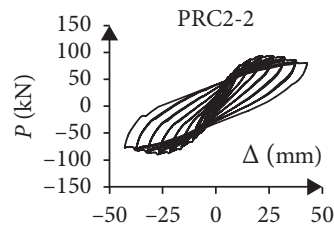

(e)

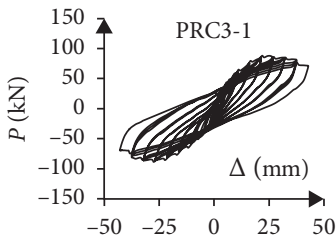

(f)

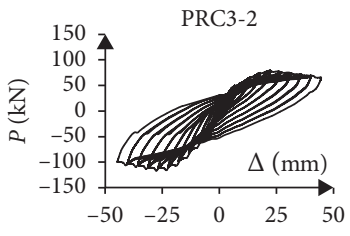

(g)

FIgURE 8: Hysteresis curves of horizontal load and displacement $(P-\Delta)$ of specimens: (a) specimen RC, (b) specimen PRC1-1, (c) specimen PRC1-2, (d) specimen PRC2-1, (e) specimen PRC2-2, (f) specimen PRC3-1, and (g) specimen PRC3-2. 
ductility of the fabricated specimen is better than that of cast-in-place specimen RC.

(3) By comparing the hysteretic curves of PRC1-1, PRC2-1, and PRC3-1, it can be found that when connection mode A is used, with the increase of the thickness of the steel plate of the connector, the peak load of the specimen decreases, and the displacement at the peak load increases gradually, and the maximum difference of the peak load is $11.6 \%$. By comparing the hysteretic curves of PRC1-2, PRC2-2, and PRC3-2, it can be found that the relationship between the peak load and displacement of the specimen is $P_{\text {maxPRC3-2 }}>P_{\text {maxPRC1-2 }}>P_{\text {maxPRC2-2 }}$, and the displacement of the specimen under the peak load is $\Delta_{\text {maxPRC2-2 }}>\Delta_{\operatorname{maxPRC1-2}}>\Delta_{\operatorname{maxPRC} 3-2}$. The maximum difference between the peak load and the peak load is $6.13 \%$. Therefore, when connection mode B is used, the peak load and displacement of the specimen under the peak load do not increase with the increasing thickness of the steel plate of the connector. At the same time, when connection method A or B is adopted, the plumpness of the hysteretic curve of each specimen has no obvious difference, and the descending section of the hysteretic curve is gentle, and the difference is small. Therefore, in the same connection mode, the thickness of the steel plate has little effect on the hysteretic properties of the specimens.

(4) When the hysteretic curves of PRC1-1 and PRC1-2, PRC2-1 and PRC2-2, and PRC3-1 and PRC3-2 are compared, it can be seen that the peak bearing capacity of PRC1-2 and PRC2-2 is $4.53 \%$ and $4.57 \%$ lower than that of PRC1-1 and PRC2-1, respectively, but the peak bearing capacity of PRC $3-1$ is $10.83 \%$ higher than that of PRC3-2. It indicates that when the thickness of the steel plate is the same, the bearing capacity of the prefabricated specimens with connection mode $\mathrm{A}$ and connection mode $\mathrm{B}$ is the same. Compared with the specimens with connection mode $A$, the fullness of the hysteretic curve of the fabricated specimens with connection mode $B$ is better, the bearing capacity and stiffness degradation are slower, and the ultimate displacement angle is larger. This is because the longer length of the connector can effectively restrain the concrete at the root of the specimen and improve the hysteretic performance of the specimen.

3.4. Skeleton Curves. The skeleton curve is the line connecting the peak points of cyclic load (the first cycle after yielding) in the hysteretic curve, which can reflect the bearing capacity, ductility, stiffness, and other information of the specimen from a macroperspective. The skeleton curve of each specimen is shown in Figure 9.

From Figure 9, it is concluded that

(1) When the displacement angle is less than $1 / 200$, the skeleton curves develop linearly, and the slope of skeleton curves of each specimen is the same. It indicates that the initial stiffness of each specimen is the same. After that, with the increase of loading displacement angle, the slope of skeleton curves gradually decreases, which is due to the gradually increased number of cracks and the stiffness degradation of specimens. After the peak load, the skeleton curves of each specimen enter the descending section, and the stiffness decreases.

(2) When the displacement angle is $1 / 35$, the skeleton curve of cast-in-place specimen RC drops sharply, showing obvious stiffness degradation. This is caused by the sudden crushing of the concrete at the root of the side of cast-in-place specimen RC. The descending sections of skeleton curves of all fabricated specimens are gentle, and there is no obvious degradation of bearing capacity and stiffness. Compared with cast-in-place specimen RC, the bearing capacity and stiffness of the fabricated specimens are more stable, and the ductility is better.

(3) Comparing the skeleton curves of PRC1-1, PRC2-1, and PRC3-1 and PRC1-2, PRC2-2, and PRC3-2, it is seen that the rising section of the skeleton curve of the specimen is coincident, and the slope of the descending section is similar. It suggests that, in the same connection mode, changing the thickness of the steel plate of the connector has little effect on the bearing capacity, ductility, and deformation performance of the specimens.

(4) Compared with the skeleton curve of PRC3-1 and PRC3-2, it can be seen that, at the same thickness of the steel plate, the larger the length of the connector, the greater the slope of the rising section of the skeleton curve, the greater the initial stiffness, the smoother the descending section of the curve, and the better the ductility performance.

3.5. Bearing Capacity and Ductility. In this study, the equivalent energy method [14] is used to determine the yield displacement $\Delta_{y}$ and yield load $P_{y}$ of the specimens. The peak load $P_{\max }$ and peak displacement $\Delta_{\max }$ are the corresponding load and displacement when the specimen reaches the maximum bearing capacity. The ultimate displacement $\Delta_{u}$ is the corresponding displacement value when the horizontal load drops to $85 \%$ of the peak load, and $\theta_{u}$ is the ultimate displacement angle. The ductility coefficient is the ratio of horizontal displacement to yield displacement at the failure of the specimens, i.e., $\mu_{u}=\Delta_{u} / \Delta_{y}$. The calculation results are shown in Table 3 . The values in the table are the average values of displacement, displacement angle, and displacement ductility coefficient under forward and reverse loading. From Table 3, it is concluded that

(1) The peak load of the fabricated specimen is $83.24 \%-$ $94.23 \%$, which indicates that the bearing capacity of the fabricated specimen is slightly lower than that of the cast-in-place specimen. The ductility coefficient of the fabricated specimen is 1.11-1.27 times of that 


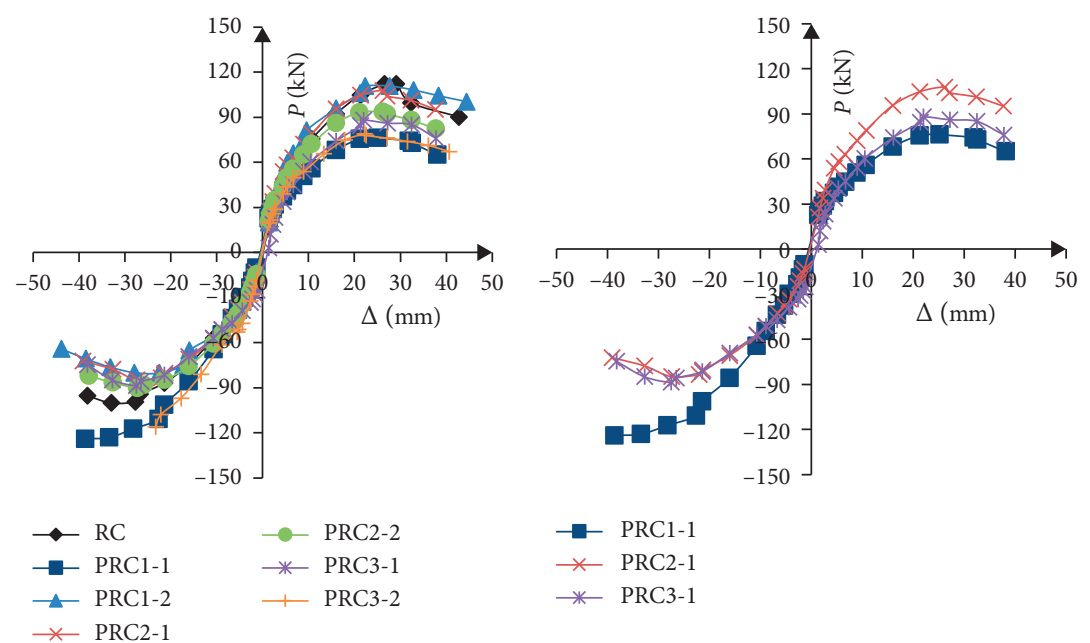

(a)

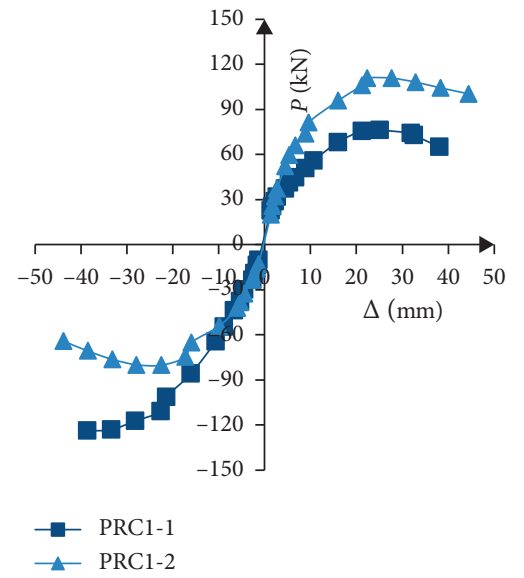

(d) (b)

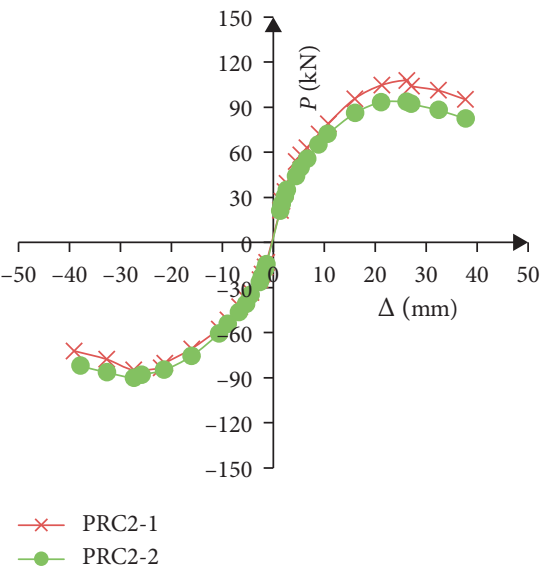

(e)

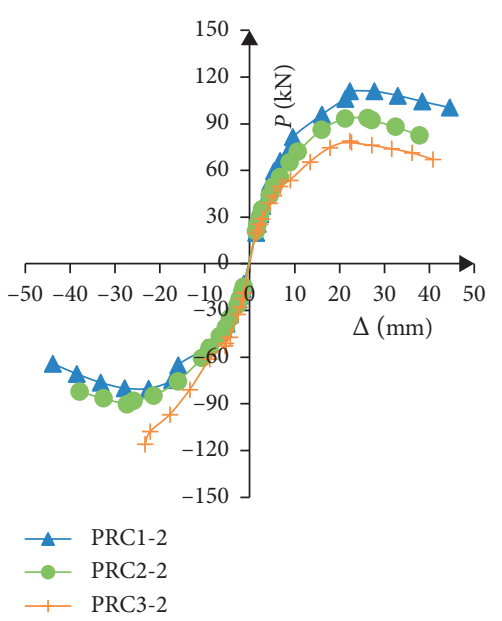

(c)

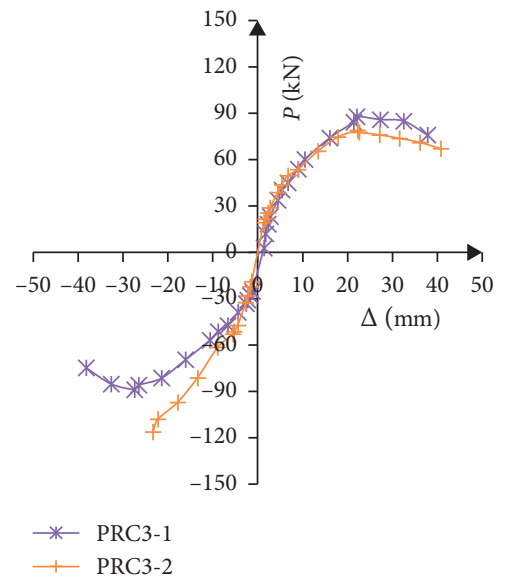

(f)

Figure 9: Comparison of skeleton curves of different specimens.

TABLE 3: Load-carrying capacity and deformation capacity of specimens.

\begin{tabular}{|c|c|c|c|c|c|c|c|c|}
\hline Specimen no. & $P_{y}(\mathrm{kN})$ & $\Delta_{y}(\mathrm{~mm})$ & $P_{\max }(\mathrm{kN})$ & $\Delta_{\max }(\mathrm{mm})$ & $P_{u}(\mathrm{kN})$ & $\Delta_{u}(\mathrm{~mm})$ & $\theta_{u}$ & $\mu$ \\
\hline $\mathrm{RC}$ & 80.21 & 15.05 & 106.16 & 31.01 & 91.93 & 40.00 & $1 / 33.75$ & 2.66 \\
\hline PRC1-1 & 70.81 & 13.75 & 100.03 & 31.90 & 92.97 & 40.49 & $1 / 33.34$ & 2.96 \\
\hline PRC1-2 & 76.23 & 13.58 & 95.50 & 25.09 & 84.29 & 42.54 & $1 / 31.01$ & 3.14 \\
\hline PRC2-1 & 76.27 & 13.62 & 96.34 & 26.82 & 81.90 & 41.02 & $1 / 32.91$ & 3.03 \\
\hline PRC2-2 & 72.68 & 12.99 & 91.94 & 26.75 & 77.98 & 42.89 & $1 / 31.48$ & 3.32 \\
\hline PRC3-1 & 65.25 & 13.38 & 88.37 & 24.73 & 73.08 & 40.35 & $1 / 33.46$ & 3.04 \\
\hline PRC3-2 & 71.91 & 12.75 & 97.94 & 24.94 & 83.21 & 42.66 & $1 / 31.65$ & 3.37 \\
\hline
\end{tabular}

of cast-in-place specimen RC, and the ultimate displacement angle of the fabricated specimen is greater than that of cast-in-place specimen RC. Thus, the ductility of the fabricated specimen is better than that of cast-in-place specimen RC.

(2) The ductility coefficients of PRC1-2, PRC2-2, and PRC3-2 are 6.1\%, 9.6\%, and 10.9\% higher than those of PRC1-1, PRC2-1, and PRC3-1, respectively. It indicates that the longer the connector length, the better the ductility of the fabricated specimen.
(3) The ductility coefficients of PRC2-1 and PRC3-1 are $2.4 \%$ and $2.7 \%$ higher than those of PRC1-1, and the ductility coefficients of PRC2-2 and PRC3-2 are 5.7\% and $7.3 \%$ higher than those of PRC1-2, respectively. It shows that, in the same connection mode, the ductility of assembled specimens can be improved by increasing the thickness of steel plates of connection base metal; the ductility improvement range of specimens with connection mode B is slightly greater than that of specimens with connection mode 
A. When the thickness of the steel plate is more than $6 \mathrm{~mm}$, the ductility of the specimens has little difference.

(4) The peak load of PRC2-1 and PRC3-1 is $96.31 \%$ and $88.4 \%$ of that of PRC1-1, and the peak load of PRC22 and PRC3-2 is $96.3 \%$ and $103 \%$ of that of PRC1-2; the ratio of peak load of PRC1-2, PRC2-2, and PRC32 to peak load of PRC1-2, PRC2-2, and PRC3-2 is $0.955,0.954$, and 1.108 , respectively. It shows that the thickness of the steel plate and the length of the connector have little influence on the bearing capacity of the fabricated specimen. Although the size of the connector of PRC1-1 is the smallest and the thickness of the steel plate connecting the base metal is the smallest, the peak load is the largest. This is because the weld fracture in the connection area of the specimen during the test leads to the rotation point of the specimen moving up, which in turn leads to the decrease of the loading height of the specimen.

3.6. Horizontal Stiffness Degradation. The secant stiffness $K$ can be used to measure the horizontal stiffness of the specimen at different horizontal displacement angles. In this study, $K_{j}=\left(\left(\left|+P_{j}\right|+\left|-P_{j}\right|\right) /\left(\left|+\Delta_{j}\right|+\left|-\Delta_{j}\right|\right)\right)$ is used, where $K_{\mathrm{j}}$ is the stiffness under the $j$-level load, $+P_{\mathrm{j}}$ and $-P_{\mathrm{j}}$ are the maximum values of forward and reverse horizontal loads under the $j$-level load, respectively, and $+\Delta_{j}$ and $+\Delta_{j}$ are the displacement values corresponding to the maximum load under the $j$-level load.

According to the calculation results, the curve of horizontal secant stiffness versus displacement is shown in Figure 10. The curve distribution in the figure shows that the secant stiffness of the specimen decreases with the increase of the loading displacement. Before the specimen yields, the stiffness degradation rate is larger, and after the specimen yield, the stiffness degradation rate is small. Compared with the cast-in-place specimen, the stiffness degradation rate of the fabricated specimen is smaller before yielding and is larger after yielding. At the same thickness of the steel plate of the connector, the horizontal secant stiffness of the fabricated specimen with connection mode B is greater than that of the fabricated specimen with connection method A. In the same connection mode, the thicker the steel plate of the connector, the greater the horizontal secant stiffness of the specimen.

The secant stiffness $K$ of the specimen at different displacement angles is given in Table 4. $\gamma$ represents the stiffness degradation coefficient calculated by taking the secant stiffness at the displacement angle of $1 / 1000$ as the cardinal number. The experimental data show that (1) when the displacement angle is small, the degradation rate of secant stiffness $K$ is faster, and the degradation rate of secant stiffness $K$ decreases gradually with the increase of displacement angle; (2) the initial stiffness of PRC1-2, PRC2-2, and PRC3-2 is $99.3 \%, 103 \%$, and $103 \%$ of that of PRC1-2, PRC2-2, and PRC3-2, respectively. Therefore, when the steel plate thickness is the same, the initial stiffness of the specimen with connection mode $\mathrm{B}$ is slightly higher than that of the specimen with connection mode A. The initial stiffness of PRC3-2 and PRC2-2 is $16.7 \%$ and $8.1 \%$ higher than that of PRC1-2, respectively, and the initial secant stiffness of PRC3-1 and PRC2-1 is $12.6 \%$ and $4.2 \%$ higher than that of PRC1-1. It indicates that, in the same connection mode, the thicker the steel plate of the connector, the greater the initial stiffness of the fabricated specimen; (3) in the same connection mode, the thickness of the steel plate of the connector has little influence on the stiffness degradation rate of the assembled specimen; at the same thickness of the steel plate, the longer the connection length, the smaller the secant stiffness degradation rate of the fabricated specimen; (4) the secant stiffness degradation rate of PRC1-2 is the minimum and that of PRC3-1 is the largest; (5) when the displacement angle is $1 / 150$, the secant stiffness of most specimens has degraded to less than $50 \%$ of the initial secant stiffness; and (6) the secant stiffness value and secant stiffness degradation law of PRC2-2 have the best coincidence with cast-in-place specimen RC.

3.7. Energy Consumption Capacity. Energy dissipation capacity is an important index to evaluate the seismic performance of frame columns. According to the provisions of specifications for seismic test of buildings (JGJ/T 101-2015) [15], the energy dissipation capacity of specimens at different displacement angles can be measured by cumulative hysteretic energy dissipation $E$, energy dissipation coefficient $e$, and equivalent viscous damping coefficient $h_{e}$, and $h_{e}=e / 2 \pi$. To unify the calculation standard, only the test results of the first hysteretic loop of each loading displacement angle are counted in calculating each index. Table 5 shows the calculation results of each specimen at different displacement angles, Figure 11 shows the cumulative energy consumption value of each specimen, and Figure 12 shows the distribution law of equivalent viscous damping coefficient of each specimen.

It can be seen from Table 5 and Figure 11 that (1) the hysteretic energy consumption $E$ of specimens increases with the increase of the loading displacement angle. When the loading displacement angle is less than $1 / 200$, the hysteretic energy consumption of the fabricated specimen is less than that of cast-in-place specimen RC. When the loading displacement angle is greater than $1 / 50$, the hysteretic energy consumption of the fabricated specimen is greater than that of cast-in-place specimen RC. It shows that the energy dissipation capacity of the assembled specimens is better than that of cast-in-place specimen RC in the later period of seismic action; (2) compared with the test pieces PRC1-1, PRC2-1, and PRC3-1, the cumulative hysteretic energy consumption E of PRC1-2, PRC2-2, and PRC3-2 is increased by $15.0 \%, 13.3 \%$, and $21.9 \%$, respectively. Thus, when the thickness of the steel plate of the connector is the same, the longer the connection length, the stronger the energy consumption capacity of the assembled specimen; and (3) the cumulative hysteretic energy consumption of PRC2-1 and PRC $3-1$ is increased by $4.6 \%$ and $8.1 \%$ compared with that of PRC1-1, and the cumulative hysteretic energy consumption of PRC2-2 and PRC3-2 is increased by $3.0 \%$ and 


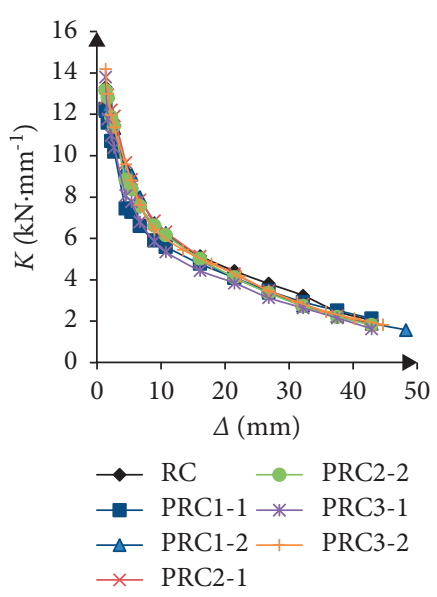

(a)

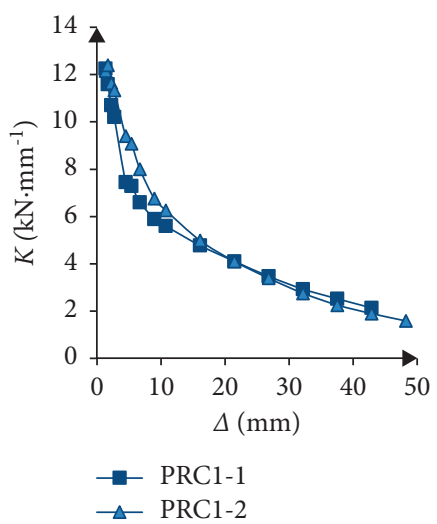

(d)

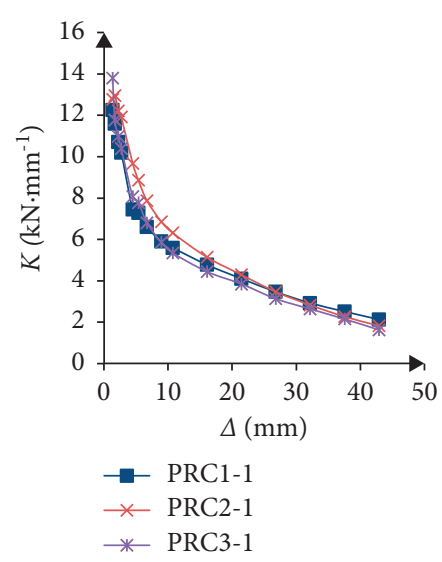

(b)

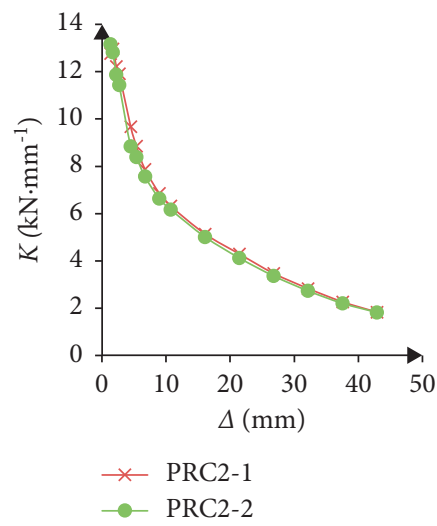

(e)

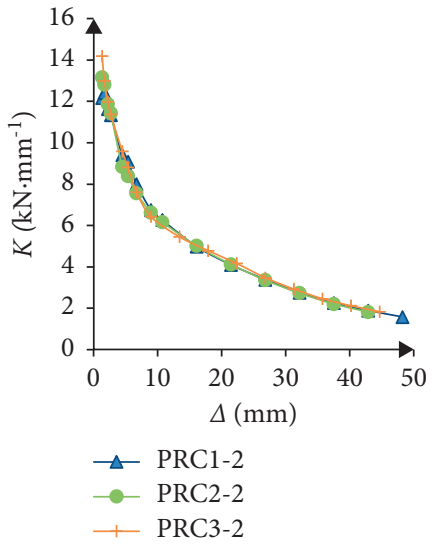

(c)

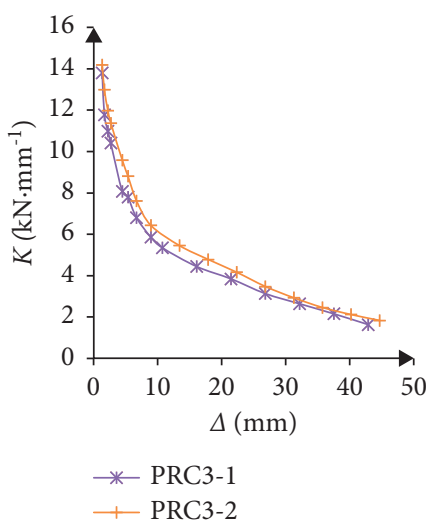

(f)

FIgURE 10: Secant stiffness-displacement curves $(K-\Delta)$ of specimens.

TABLE 4: Secant stiffness $K(\mathrm{kN} / \mathrm{mm})$ and secant stiffness degradation coefficient $\gamma(\%)$ of specimens.

\begin{tabular}{lcccccccccccccc}
\hline \multirow{2}{*}{ Specimen no. } & $1 / 1000$ & \multicolumn{2}{c}{$1 / 500$} & \multicolumn{2}{c}{$1 / 200$} & \multicolumn{2}{c}{$1 / 150$} & \multicolumn{2}{c}{$1 / 100$} & \multicolumn{2}{c}{$1 / 50$} & \multicolumn{4}{c}{$1 / 30$} \\
& $K$ & $K$ & $\gamma$ & $K$ & $\gamma$ & $K$ & $\gamma$ & $K$ & $\gamma$ & $K$ & $\gamma$ \\
\hline RC & 13.30 & 11.46 & 86.2 & 7.53 & 56.6 & 6.61 & 49.7 & 5.65 & 42.5 & 3.82 & 28.7 & 2.04 & 15.3 \\
PRC1-1 & 12.26 & 10.20 & 83.2 & 6.61 & 53.9 & 5.90 & 48.1 & 5.19 & 42.3 & 3.45 & 28.1 & 2.13 & 17.4 \\
PRC1-2 & 12.17 & 11.34 & 93.2 & 7.99 & 65.7 & 6.76 & 55.5 & 5.62 & 46.2 & 3.39 & 27.9 & 1.89 & 15.5 \\
PRC2-1 & 12.77 & 11.92 & 93.3 & 7.88 & 61.7 & 6.86 & 53.7 & 5.73 & 44.9 & 3.47 & 27.1 & 1.83 & 14.3 \\
PRC2-2 & 13.15 & 11.43 & 86.9 & 7.56 & 57.5 & 6.23 & 47.4 & 5.59 & 42.5 & 3.36 & 25.6 & 1.82 & 13.8 \\
PRC3-1 & 13.81 & 10.40 & 75.3 & 6.80 & 49.2 & 5.86 & 42.4 & 4.89 & 35.4 & 3.13 & 22.7 & 1.63 & 11.8 \\
PRC3-2 & 14.19 & 11.38 & 80.2 & 7.62 & 53.7 & 6.43 & 45.3 & 5.45 & 38.4 & 3.48 & 24.5 & 1.83 & 12.9 \\
\hline
\end{tabular}

$14.6 \%$ compared with that of PRC1-2. It indicates that, in the same connection mode, the prefabricated specimen with a thicker steel plate has a stronger energy dissipation capacity.

It can be seen from Figure 12 that (1) before yielding, the equivalent damping coefficient $h_{\mathrm{e}}$ fluctuates with the increase of loading displacement, which is mainly due to the cracking of the specimen and the decrease of horizontal stiffness. When the horizontal load is unloaded to zero, the specimen has residual deformation; the hysteretic curve of the specimen presents a parallelogram, and the $h_{\mathrm{e}}$ value is larger. With the increase of horizontal load and the interlocking of concrete aggregate, the bearing capacity of the specimens increases, and the hysteretic curve presents the shape of an elongated parallelogram, and the $h_{\mathrm{e}}$ value decreases slightly with the increase of loading displacement; (2) after the specimens yield, the interlocking of concrete aggregate is fully exerted, and the longitudinal reinforcement yields and enters the strengthening section, and the $h_{e}$ value increases continuously; (3) the $h_{\mathrm{e}}$ value of the fabricated specimen increases; (4) by comparing the $h_{\mathrm{e}}$ values of PRC1-2, PRC2-2, and PRC3-2, it can be seen that, in the same connection mode, the thicker the steel plate of the connector, the greater the $h_{\mathrm{e}}$ value of the assembled specimen and the stronger the energy dissipation capacity of the specimen; and (5) by comparing the $h_{\mathrm{e}}$ values of PRC3-1 and PRC3-2, it can be seen that when the thickness of the steel plate of the connector is the same, the longer the connector length, the stronger the 
TABle 5: Cumulative hysteretic energy dissipation $E(\mathrm{kN} \cdot \mathrm{mm})$, energy dissipation coefficient $e$, and equivalent viscous damping coefficient $h_{e}$ of specimens.

\begin{tabular}{lcccccccc}
\hline Specimen no. & & RC & PRC1-1 & PRC1-2 & PRC2-1 & PRC2-2 & PRC3-1 & PRC3-2 \\
\hline \multirow{3}{*}{$1 / 500$} & $E$ & 0.050 & 0.016 & 0.041 & 0.049 & 0.048 & 0.046 \\
& $e$ & 0.606 & 0.708 & 0.508 & 0.569 & 0.583 & 0.618 & 0.044 \\
& $h_{e}$ & 0.096 & 0.113 & 0.081 & 0.091 & 0.093 & 0.098 \\
$1 / 200$ & $E$ & 0.251 & 0.226 & 0.212 & 0.262 & 0.166 & 0.233 \\
& $e$ & 0.739 & 0.761 & 0.589 & 0.742 & 0.689 & 0.765 & 0.086 \\
\hline \multirow{3}{*}{$1 / 150$} & $h_{e}$ & 0.118 & 0.121 & 0.094 & 0.118 & 0.110 & 0.122 & 0.717 \\
& $E$ & 0.371 & 0.349 & 0.362 & 0.934 & 0.359 & 0.358 \\
\hline \multirow{3}{*}{$1 / 125$ (PRC3-2: 1/100) } & $e$ & 0.703 & 0.741 & 0.670 & 0.720 & 0.678 & 0.766 \\
& $h_{e}$ & 0.112 & 0.118 & 0.107 & 0.115 & 0.108 & 0.122 \\
\hline \multirow{3}{*}{$1 / 50$} & $E$ & 0.462 & 0.426 & 0.436 & 0.494 & 0.448 & 0.471 \\
& $e$ & 0.654 & 0.661 & 0.605 & 0.680 & 0.633 & 0.766 \\
& $h_{e}$ & 0.104 & 0.105 & 0.096 & 0.108 & 0.101 & 0.122 \\
\hline \multirow{3}{*}{$1 / 30$} & $E$ & 1.798 & 1.910 & 2.279 & 2.124 & 2.029 & 1.908 \\
& $e$ & 0.656 & 0.767 & 0.937 & 0.853 & 0.841 & 0.848 \\
\hline
\end{tabular}

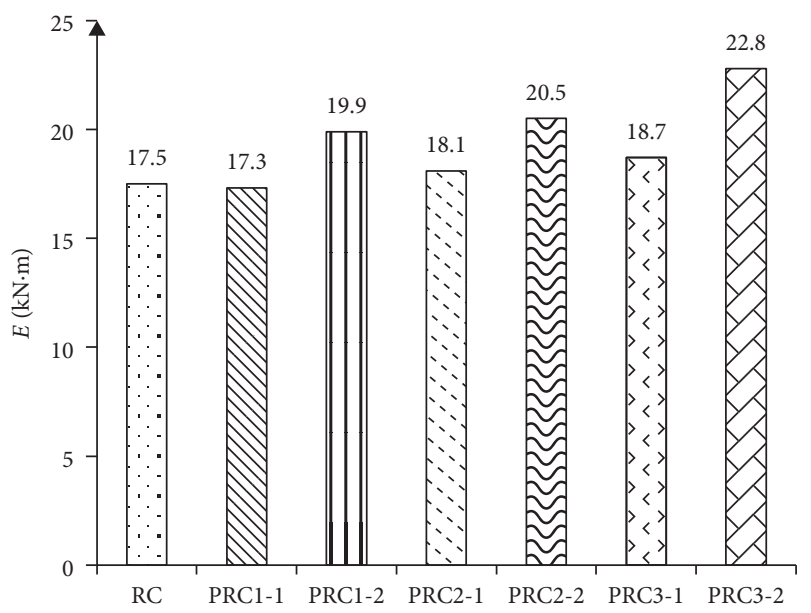

FIgURE 11: Comparison of cumulative energy consumption of specimens.

energy dissipation capacity of the assembled specimen.

3.8. Bearing Capacity Degradation. Under the same displacement amplitude, the phenomenon that the bearing capacity of the specimen decreases with the increase of cyclic loading times is called bearing capacity degradation, which is represented by $\Phi_{i}$. According to $\Phi_{\mathrm{i}}=P_{j-i} / P_{j-1}$, the bearing capacity degradation rate of each specimen is calculated [15], where $P_{j-i}$ is the average value of the absolute value of forward and reverse peak loads of the $i$-th cycle under the $j$-level displacement amplitude; $P_{j-1}$ is the average value of the absolute value of the forward and reverse peak loads of the first cycle under the $j$-level displacement amplitude. The calculation results of bearing capacity degradation rate of each specimen under different displacement angles are shown in Table 6.

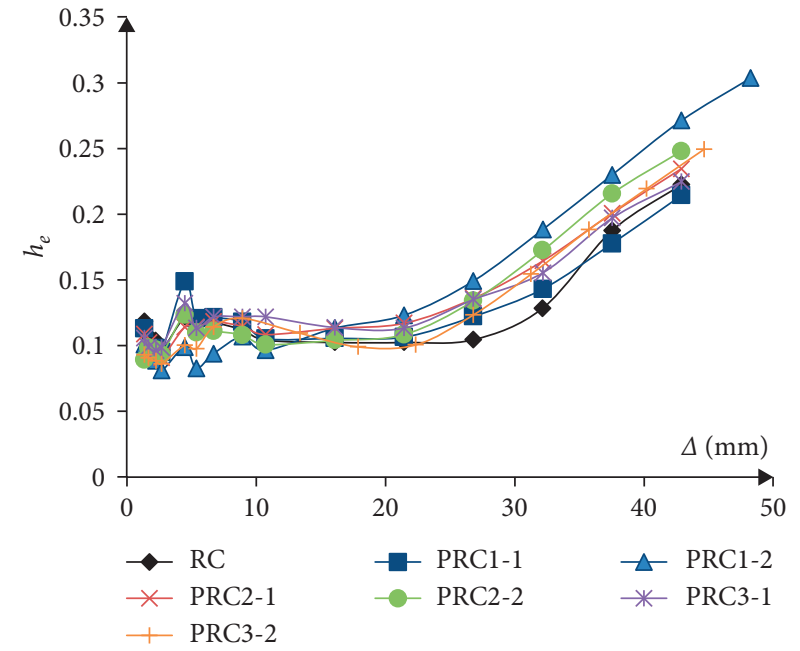

FIGURE 12: Equivalent viscous damping coefficient displacement $\left(h_{e}-\Delta\right)$ curve.

It can be seen from Table 6 that (1) the attenuation of bearing capacity of each specimen increases with the increase of loading displacement angle, and the degradation range of bearing capacity increases with the increase of loading times; (2) the maximum bearing degradation rate of cast-in-place specimen RC is $8.6 \%$, and the maximum bearing capacity degradation rate of PRC1-1-PRC3-2 is 5.9\%-10.3\%. It indicates that there is no obvious difference between the degradation law of the assembled specimens and that of cast-in-place specimen RC; (3) the maximum bearing capacity degradation amplitude of PRC1-1, PRC2-1, and PRC3-1 is 5.9\%, 7.5\%, and $9.9 \%$, respectively. The maximum bearing capacity degradation amplitude of PRC1-2, PRC2-2, and PRC3-2 is $8.3 \%, 7.0 \%$, and $6.5 \%$, respectively. It can be seen that, in the same connection mode, the influence of the thickness of the base plate of the 
TABLE 6: Degradation rate of bearing capacity $\Phi_{i}$ of each specimen under different displacement amplitudes.

\begin{tabular}{ccccccccc}
\hline \multicolumn{2}{c}{ Specimen no. } & RC & PRC1-1 & PRC1-2 & PRC2-1 & PRC2-2 & PRC3-1 & PRC3-2 \\
\hline \multirow{2}{*}{$1 / 60$} & $i=2$ & 0.995 & 0.999 & 0.988 & 0.994 & 0.990 & 0.999 \\
& $i=3$ & 0.996 & 0.997 & 0.991 & 0.992 & 0.986 & 0.996 \\
\multirow{2}{*}{$1 / 50$} & $i=2$ & 0.992 & 0.990 & 0.959 & 0.969 & 0.987 & 0.977 \\
& $i=3$ & 0.973 & 0.986 & 0.955 & 0.965 & 0.983 & 0.978 \\
\multirow{2}{*}{$1 / 40$} & $i=2$ & 0.942 & 0.984 & 0.934 & 0.948 & 0.957 & 0.975 \\
& $i=3$ & 0.951 & 0.982 & 0.928 & 0.937 & 0.948 & 0.969 \\
\multirow{2}{*}{$1 / 35$} & $i=2$ & 0.924 & 0.950 & 0.922 & 0.937 & 0.939 & 0.930 \\
\multirow{2}{*}{$1 / 30$} & $i=3$ & 0.914 & 0.941 & 0.917 & 0.925 & 0.930 & 0.964 \\
& $i=2$ & 0.952 & - & 0.909 & - & - & 0.943 \\
& $i=3$ & 0.945 & - & 0.897 & - & - & 0.942 \\
& & & & & & - & 0.935 \\
\end{tabular}

connecting part on the bearing capacity degradation is not obvious; and (4) the maximum bearing capacity degradation amplitude of PRC1-2, PRC2-2, and PRC3-2 is decreased by $-2.4 \%, 0.5 \%$, and $3.4 \%$, respectively, compared with that of PRC1-1, PRC2-1, and PRC3-1. It can be seen that when the thickness of the steel plate of the connector is the same, the length of the connector has no significant influence on the bearing capacity degradation.

\section{Conclusion}

In this study, the length of the connector and the thickness of the steel plate of the base material of the connector are considered, and the seismic performance of six prefabricated reinforced concrete column specimens with steel mortise and tenon connections and one cast-in-place reinforced concrete column specimen is tested and studied. The main conclusions are as follows:

(1) The results show that the bearing capacity of the fabricated reinforced concrete column with the steel tenon-mortise connection is $5.77 \%-16.76 \%$ lower than that of the cast-in-place reinforced concrete column; compared with the cast-in-place specimen, the ductility coefficients of fabricated specimens are increased by $11.28 \%-26.69 \%$, the energy consumption capacity of PRC1-1 is reduced by $1.14 \%$, and the energy consumption capacity of other fabricated specimens is increased by $3.4 \%-30.29 \%$. Although the bearing capacity of the prefabricated reinforced concrete columns with the steel tenon-mortise connection is slightly lower than that of cast-in-place reinforced concrete columns, the ductility and energy dissipation capacity are improved.

(2) The ultimate displacement angle of the fabricated reinforced concrete column with the steel tenonmortise connection is $1 / 33.46-1 / 31.01$, which is higher than that of the cast-in-place reinforced concrete column specimen. It indicates that the fabricated reinforced concrete column with the steel tenon-mortise connection has good collapse resistance.

(3) The length of connectors and the thickness of the steel plate have little influence on the bearing capacity of the assembled reinforced concrete column.
The longer the connector length or the thicker the steel plate, the greater the ductility and energy dissipation capacity of the assembled specimens.

(4) The longer the length of the connector, the greater the initial stiffness and the smaller the stiffness degradation rate. The steel plate thickness of the connector has little influence on the stiffness degradation rate of assembled reinforced concrete column specimens.

(5) Under the action of low cycled reversed loading, the failure process and failure mode of the prefabricated reinforced concrete column specimens and cast-inplace reinforced concrete column specimens are the same, and the bending failure is observed. In the process of test, weld fracture occurs in the connection area of PRC1-1, and the connectors of other fabricated reinforced concrete column specimens are kept in good condition. Therefore, it is suggested that when the length of the connector is $100 \mathrm{~mm}$ (connection mode $\mathrm{A}$ ), the thickness of the steel plate of the connector shall not be less than $6 \mathrm{~mm}$.

\section{Data Availability}

The data used to support the findings of this study are included within the article.

\section{Conflicts of Interest}

The authors declare that they have no conflicts of interest.

\section{Acknowledgments}

The work in this paper was supported by the Natural Science Foundation of the Jiangsu Higher Education Institutions of China (16KJB560016) and Suqian Science and Technology Project (H201620 and Z2019107). The support is gratefully acknowledged.

\section{References}

[1] W. C. Xue, "Progress of studies and applications of precast concrete frame structure systems," Industrial Construction, vol. 32, no. 11, pp. 47-50, 2002.

[2] Z. F. Zhu and Z. X. Guo, "Experiments on hybrid precast concrete shear walls emulating monolithic construction with 
different amounts of posttensioned strands and different debond lengths of grouted reinforcements," Advances in Materials Science and Engineering, vol. 2016, Article ID 6802503, 13 pages, 2016.

[3] M. E. Rodriguez and J. J. Blandon, "Tests on a half-scale twostory seismic-resisting precast concrete building," PCI Journal, vol. 50, no. 1, pp. 94-114, 2005.

[4] J. H. Khoo, B. Li, and W. K. Yip, "Tests on precast concrete frames with connections constructed away from column faces," ACI Structural Journal, vol. 103, no. 1, pp. 18-27, 2006.

[5] Y. C. Kurama, B. D. Weldon, and Q. Shen, "Experimental evaluation of posttensioned hybrid coupled wall subassemblages," Journal of Structural Engineering, vol. 132, no. 7, pp. 1017-1029, 2006.

[6] G. W. Rodgers, K. M. Solberg, J. B. Mander, J. G. Chase, B. A. Bradley, and R. P. Dhakal, "High-force-to-volume seismic dissipators embedded in a jointed precast concrete frame," Journal of Structural Engineering, vol. 138, no. 3, pp. 375-386, 2012.

[7] Q. N. Li, X. C. Zheng, Z. Y. Yan, W. S. Jiang, and S. B. Pan, "Seismic behavior experimental study and theoretical analysis on high-strength spiral stirrups confined concrete column," Journal of Building Structures, vol. 34, no. 8, pp. 90-99, 2013.

[8] M. Wang, S. T. Liang, K. M. Li, X. J. Zhu, and R. Pang, "Forced performances study on total-precast concrete frame column with alveolus-connection," Industrial Construction, vol. 40, no. 2, pp. 69-73, 2010.

[9] Y. Liu, Z. X. Guo, Y. T. Lv, Q. X. Huang, and Z. Y. Wang, "Experimental study on seismic behavior of full-scale PRC columns with new mechanical splice technique for longitudinal reinforcement," Journal of Building Structures, vol. 38, no. 11, pp. 101-110, 2017.

[10] Y. Liu, Z. X. Guo, Q. M. Liu, and J. L. Fu, "Experimental study on the axial compression behavior of the prefabricated RC columns linked at middle region at different stages of construction," Engineering Mechanics, vol. 32, no. 12, pp. 208214, 2015.

[11] J. Yan, Z. L. Li, and S. C. Li, "Pseudo-static test research on prefabricated welded stirrup concrete columns with steel notch-tooth connection," Industrial Construction, vol. 48, no. 12, pp. 96-102, 2018.

[12] J. Yan, K. Q. Wang, H. Y. Luo, H. H. Lv, and S. C. Li, "Experiment on seismic behavior of prefabricate concrete columns with steel notch-tooth connection," Journal of Civil Engineering and Management, vol. 36, no. 5, pp. 73-80, 2019.

[13] L. J. Jiang and G. L. Bai, "Experimental study on cumulative damage behavior of steel-reinforced concrete columns," Advances in Civil Engineering, vol. 2020, Article ID 5281725, 16 pages, 2020.

[14] X. Y. Sun, Experimental Study on the Seismic Performance of Frame Beam with Simulating the Long-Period Seismic Loads, Beijing University of Technology, Beijing, China, 2013.

[15] JGJ/T 101-2015 Specification for Seismic Test of buildings, China Architecture \& Building Press, Beijing, China, 2015. 